Çukurova Üniversitesi Mühendislik Mimarlık Fakültesi Dergisi, 30(2), 125-135 ss., Aralık 2015

Çukurova University Journal of the Faculty of Engineering and Architecture, 30(2), pp. 125-135, December 2015

\title{
Seralarda Enerji Verimliliğinin Artırılması
}

\author{
A. Nafi BAYTORUN ${ }^{* 1}$, Özkan GÜGERCIN ${ }^{1}$ \\ ${ }^{1}$ Çukurova Üniversitesi, Ziraat Fakültesi Tarımsal Yapılar ve Sulama Bölümü, Adana
}

Geliş tarihi:09.12.2015

Kabul tarihi:28.12.2015

\section{Özet}

Türkiye'de son yıllarda inşa edilen seralarda ısıtma yapılmaktadır. Seralarda 1sıtma ürün verimini, kalitesini ve miktarını yükseltmektedir. Özellikle Akdeniz sahil şeridinde 1sıtılan seralarda iki kat verim artışı sağlanabilmektedir. Ancak 1sı koruma önlemlerinin alınmadığı seralarda 1sı enerjisi gereksinimi artmakta ve üretim periyodu boyunca bölgenin iklim değerlerine bağlı olarak ortalama $100 \mathrm{kWh} . \mathrm{m}^{-2} \cdot \mathrm{a}^{-1}$ ısı enerjisine ihtiyaç duyulmaktadır. Artan enerji maliyetleri, üreticinin ısıtmanın karlılığını tartışmasına neden olmaktadır. Belirtilen nedenle seralarda isitma kadar, isitılan seralarda enerji korunumu da karlılık ve enerji verimliliği açısından önem arz etmektedir.

Bu çalışmada, Türkiye'de seracılığın yoğun olarak yapıldığı Antalya ilinin uzun yıllık (1962-2012) iklim değerleri kullanılarak, PE plastik örtülü seralarda, farklı 1Sı koruma önlemlerine bağlı olarak, gereksinilen 1sı enerjisi değerleri ve tasarruf oranları belirlenmiştir. Yapılan hesaplamalar sonucunda 1sıtılan seralarda 1s1 koruma önlemlerine bağlı olarak, \%40 oranında 1s1 enerjisinin tasarruf edilebileceği belirlenmiştir.

Anahtar Kelimeler: Sera, Sera 1sıtması, Enerji tasarrufu, Isı perdesi

\section{Increasing the Energy Efficiency in Greenhouses}

\begin{abstract}
Heating systems are applied in greenhouses lately constructed in Turkey. Heating in greenhouses increases efficiency, quality and output quantity. Efficiency doubled especially in heated greenhouses on the Mediterranean coast. However in greenhouses where heat loss precautionary measures are not taken, heat energy demand increases and an average heat energy of $100 \mathrm{kWh} \cdot \mathrm{m}^{-2} \cdot \mathrm{a}^{-1}$ is needed. On the other hand increasing energy costs cause the producers to question the profitability of heating. For that reason reducing the energy losses in heated greenhouses is as important as heating the greenhouses in terms of profitability and energy efficiency.

\footnotetext{
* Yazışmaların yapılacağı yazar: A.Nafi Baytorun, Çukurova Üniversitesi, Ziraat Fakültesi Tarımsal Yapılar ve Sulama Bölümü,Adana, baytorun@cu.edu.tr
} 
In this study the required levels of heat energy and disposition rates for PE covered greenhouses are identified by using the yearly climate values of Antalya (from 1962 to 2012) where greenhousing is widespread. According to the calculations, it is found that $40 \%$ heat energy saving is possible with precautionary measures in heated greenhouses.

Keywords: Greenhouse, Greenhouse heating, Energy efficiency, Termal screen

\section{GİRIŞ}

Ülkelerin geleceğe yönelik bazı gereksinimlerinin, nüfus artışı da dikkate alınarak karşılanabilmesi için, mevcut tarımsal üretimin daha verimli ve nitelikli duruma getirilmesi zorunludur. Ülkemizde tarım alanlarının son sınırına ulaşmış olması ve nüfusun hızla artması verimi artırıcı özel önlemlerin alınmasını gerekli kılmaktadır. Bu özel önlemler arasında meyve ve sebzelerin kontrollü ortamlarda (sera) ve düşük üretim maliyetleri ile yetiştirilmesi de yer almaktadır. Seracılıktaki yeni gelişmeler bu sektörde sürdürülebilirliği sağlamaya yönelik gayretler ile paralel olarak ortaya çıkmaktadır. Seraların yapısal özelliklerinin iyileştirilmesi, iklimlendirme ve alternatif enerji kaynaklarından faydalanma, kontrollü koşullarda üretim, topraksız tarımın yaygınlaştırılması, entegre hastalık ve zararlı yönetimi, sertifikalı güvenli ve izlenebilir gida üretimi şeklinde özetlenebilir.

Seralarda 1sıtma verim ve kaliteyi önemli ölçüde etkilemektedir. Ancak 1sitılan seralarda 1sı koruma önlemleri alınmadığı takdirde, soğuk dönemlerde bitkilerin arzuladığı iklim değerlerini sağlamak için, ciddi anlamda enerjiye ihtiyaç duyulmaktadır. Zabeltitz Antalya'da seraların Aralık, Ocak ve Şubat aylarında sadece gece saatlerinde 1sitılması durumunda, gerekli olan yakıt miktarını 7 L.m-2 olarak hesaplamıştır [12]. Modern seracılığın yaygın olduğu Hollanda'da bir $\mathrm{kg}$ domates üretmek için Türkiye'ye oranla 13 kat fazla yakıt tüketilmektedir [12] kullanılmıştır.

Serada üretim açık alanlara göre daha fazla miktarda enerji, su, gübre ve tarımsal ilaca gereksinim gösterirken; aynı zamanda fazla miktarda atık ve karbon emisyonu üretmektedir.
Tarım sektöründe birim alan için gereksinilen enerji miktarı en fazla seracılık işletmelerinde ortaya çıkmaktadır. Türkiye'de sera 1sıtmasında fosil enerji kaynakları kullanılmaktadır. Fosil enerji kaynakları yakıldığında, $\mathrm{CO}_{2}$ açı̆̆a çıkmaktadır. $\mathrm{CO}_{2}$ emisyonunun değeri kullanılan yakıt çeşidine ve miktarına bağlı olarak değişim göstermektedir. Horscht ve ark. $960 \mathrm{~m}^{2}$ taban alanına sahip isı perdeli cam serada tüketilen yakıta karşılık, 191 ton $\mathrm{CO}_{2}$ 'in atmosfere verildiğini; aynı koşullarda iyi izole edilen seradan atmosfere verilen $\mathrm{CO}_{2}$ emisyonu miktarının ise 160 ton olduğunu belirlemişlerdir [6]. Atmosfere karışan $\mathrm{CO}_{2}$ sera etkisini arttırmaktadır. Bilim insanları atmosferdeki bu değişimin, yerkürenin iklimini olumsuz yönde değiştireceği konusunda hemfikirler. Günümüzde kutuplarda eriyen buzulların deniz seviyesini yükseltmesi yanında, yağış sistemindeki değişikliklerin yarattığı felaketler, günlük hayatımızda sıkça yer almaya başlamıştır.

Seralarda yenilikçi teknolojilerin amacı, seracılıkta "Yaşam Döngüsü Kalitesinin" artırılmasıdır. Bu amaçla seracılıkta birim alandan elde edilecek ürün için gerekli olan enerji ve diğer girdi ve çıktılarının sağlıklı bir şekilde analiz edilmesi sürdürülebilirlik açısından büyük bir önem arz etmektedir [7], [9]. Sürdürülebilir seracilık sistemlerinin amacı; kaynakları koruyan, sosyal destekli, ticari, rekabetçi, çevreci, güvenilir üretim teknolojisine sahip, enerji, su ve kimyasal ilaç gereksinimini azaltan ve mümkün olduğu kadar atık üretmeyen bir sistem olmalıdır. $\mathrm{Bu}$ amaçla Giuliano ve arkadaşları [5];

1. Bitkiler için uygun bir üretim ortamının yaratılması ve enerji tasarrufu için, serada güneş radyasyonu, hava sicaklığı, oransal nem ve $\mathrm{CO}_{2}$ 
konsantrasyonunun etkili bir yönetimle idare edilmesini,

2. Fosil enerji kaynakları yerine, yenilenebilir enerji kaynaklarının kullanılmasını,

3. Seralarda yeni teknolojilerle üretilmiş ve kullanıldıktan sonra parçalanabilen örtü malzemesinin kullanılmasını,

4. Serada su ve bitki besin maddelerinin optimizasyonunun sağlanmasını ve

5. Serada bitki hastalıklarının daha az tarımsal ilaçlarla kontrolünü önermektedirler.

Soğuk iklim bölgelerinde kurulan seralar, y1lın uzun dönemlerinde 1sitılmak zorundadır. Ilıman iklim bölgelerinde ise, 1sıtma süresi daha kısa olup, ısıtma gereksinimi sadece kış aylarında ortaya çıkmaktadır. Akdeniz bölgesi seralarında 1S1 enerjisi gereksinimi, soğuk kuzey Avrupa ülkelerine göre daha azdır. Güney İtalya'da 1 ha'lık kesme çiçek serası için 5 200-6 800 GJ.a $^{-1}$ $\left(167 \mathrm{kWh} . \mathrm{m}^{-2^{3}} \cdot \mathrm{a}^{-1}\right)$ 1sı enerjisi gereksinimi ortaya çıkarken, Hollanda'da aynı büyüklükteki serada 1sı enerjisi gereksinimi $16000 \quad$ GJ.a $^{-1}$ (444 kWh.m $\mathrm{m}^{-2} \cdot \mathrm{a}^{-1}$ ) olmaktadir [4].

Kuzey ve güney Avrupa ülkeleriyle İsrail'de kurulan seralarda 1S1 gücü, 1S1 enerjisi gereksinimi ve yakıt tüketimleri Çizelge 1'de verilmiştir. Çizelgeden de görüleceği gibi kuzey ve güney Avrupa ülkelerinde kurulan seralarda gereksinilen yakıt miktarları ciddi anlamda yüksektir.

Kuzey Avrupa ülkelerinde ihtiyaç duyulan yakıt miktarı, güney Avrupa ülkelerinin 10-13 katı olmaktadır [3]. Kuzey Avrupa ülkelerinde kurulan seralarda 1s1 enerjisi gereksinimi $1900 \mathrm{MJ} \cdot \mathrm{m}^{-2} \cdot \mathrm{a}^{-1}$ $\left(528 \mathrm{kWh} \cdot \mathrm{m}^{-2} \cdot \mathrm{a}^{-1}\right)$ iken, bu değer Orta Avrupa ülkeleri için $1500 \mathrm{MJ} \cdot \mathrm{m}^{-2} \cdot \mathrm{a}^{-1}$ (417 $\left.\mathrm{kWh} \cdot \mathrm{m}^{-2} \cdot \mathrm{a}^{-1}\right)$, güney Avrupa ülkeleri için $500 \mathrm{MJ} \cdot \mathrm{m}^{-2} \cdot \mathrm{a}^{-1}$ (139 $\mathrm{kWh} \cdot \mathrm{m}^{-2} \cdot \mathrm{a}^{-1}$ ) olmaktadır. Kuzey Avrupa ülkelerinde $\quad 1,900 \quad \mathrm{MJ} \cdot \mathrm{m}^{-2} \cdot \mathrm{a}^{-1} \quad$ 1S1 enerjisi gereksinimi için üretim periyodu boyunca $45 \mathrm{~L} . \mathrm{m}^{-2}$ Fuel-Oil'e ihtiyaç duyulurken; bu değer orta Avrupa ülkelerinde 35 L.m ${ }^{-2}$, güney Avrupa ülkelerinde $12 \mathrm{~L} \cdot \mathrm{m}^{-2}$ olmaktadır [2].

Türkiye'nin farklı bölgelerinde bulunan bazı illerde kurulacak tek kat PE plastikle kaplı seralarda, sicaklığın gece/gündüz $16 / 18^{\circ} C^{\prime} d e$ tutulmak istenmesi durumunda, gereksinilen maksimum 1s1 gücü ve 1s1 enerjisi gereksinimleri, ISIGER uzman sistem [1] yardımı ile hesaplanarak, Çizelge 2'de verilmiştir. Çizelgeden görüleceği gibi en düşük 1si enerjisi gereksinimi Mersin'de (74 kWh.m $\left.{ }^{-2} \cdot \mathrm{a}^{-1}\right)$, en yüksek 1s1 enerjisi gereksinimi karasal iklimin hakim olduğu Nevşehir (376 $\left.\mathrm{kWh} \cdot \mathrm{m}^{-2} \cdot \mathrm{a}^{-1}\right)$ ilimizde ortaya çıkmaktadır.

Seralarda 1sitma kadar, 1sitilan seralarda enerji korunumu da önem arz etmektedir. Günümüzde sürekli artan enerji fiyatları, fosil enerji kaynaklarının atmosfere verdiği $\mathrm{CO}_{2}$ emisyonu, sera üreticilerini enerji etkinliği konusunda bir arayışa yöneltmiştir. Isıtılan seralarda, işletmenin karlılığ1 artırmak amacıyla aşağıdaki önlemlerin alınması zorunludur.

- Enerji verimliğini artırmak,

- Seralarda enerji gereksinimini azaltmak,

- Fosil enerji kaynakları yerine, yenilenebilir enerji kaynaklarını kullanmak.

Yapılan bu çalışmada, ISIGER uzman sistem yardımıyla seralarda farklı 1sı koruma önlemlerine bağlı olarak, ihtiyaç duyulan 1sı gücü ve 1sı enerjisi gereksinimi hesaplanarak, enerji verimliliğinin artırılması için alınacak önlemler özetlenmiştir [1].

\section{MATERYAL VE METOT}

Seralarda 1S1 enerjisi gereksiniminin hesaplanmas1 ISIGER uzman sistem kullanılarak yapılmıştır. ISIGER uzman sistemde seralarda 1s1 gücü ve 1s1 enerjisi gereksinimi, saatlik iklim değerlerinden (sıcaklık, güneş radyasyonu ve rüzgar hızı) gidilerek hesaplanmaktadır.

ISIGER uzman sistemin en büyük özelliği bölge iklimi, sera tipi, donanımı ve sera tipine bağlı olarak serada ortaya çıkan gerçek sıcaklık ve serada depolanan enerjiye bağlı olarak ortaya çıkan sıcaklık yükselmesinin dikkate alınmasıdır.

Çalışmada seracılığın yoğun olarak yapıldığ Antalya ili iklim değerleri hesaplamalarda esas alınmıştır. Hesaplamalarda son yıllarda Türkiye'de kurulan modern plastik sera boyutları dikkate alınmıştır. 
Çizelge 1. Kuzey ve Güney Avrupa'da kurulan seralarda enerji bütçesi [3]

\begin{tabular}{|c|c|}
\hline Avrupa Bölgesi & Is1 gücü gereksinimi $\left(\mathrm{W} . \mathrm{m}^{-2}\right)$ \\
\hline Hollanda - Almanya & 250 \\
\hline Kuzey İtalya & $150-200$ \\
\hline Orta İtalya & $100-150$ \\
\hline İsrail & $80-120$ \\
\hline Güney İtalya & $30-50$ \\
\hline \multicolumn{2}{|c|}{ Yakıt Gereksinimi kg.m ${ }^{-2} \cdot a^{-1}$ (Kalorifer Yakıtı) } \\
\hline Güney Avrupa & Kuzey Avrupa \\
\hline $5-6$ & $60-80$ \\
\hline \multicolumn{2}{|c|}{ Emisyon değeri: $1 \mathrm{~kg}$ kalorifer yakıtının kullanılması durumunda $0,5 \mathrm{~kg} \mathrm{CO}_{2}$} \\
\hline Sera & i Gereksinimi \\
\hline 2 - 3 kWh.m - $^{-2} \cdot$ gün $^{-1}\left(14-10^{\circ} \mathrm{C}\right)$ & Kuzey Avrupa \\
\hline $0,5-1$ kWh.m $\mathrm{m}^{-2} \cdot$ gün $^{-1}\left(12-10^{\circ} \mathrm{C}\right)$ & Güney Avrupa \\
\hline
\end{tabular}

Çizelge 2. Türkiye'nin farklı illerinde tek kat PE plastikle kaplı serada, sicaklığın gece/gündüz $16 / 18^{\circ} \mathrm{C}^{\prime} \mathrm{de}$ tutulmak istenmesi durumunda, maksimum 1S1 gücü, 1S1 enerjisi gereksinimi

\begin{tabular}{|l|c|c|}
\hline \multicolumn{1}{|c|}{ İler } & $\begin{array}{c}\text { Is1 gücü } \\
\text { gereksinimi } \\
\left(\mathrm{W} . \mathrm{m}^{-2}\right)\end{array}$ & $\begin{array}{c}\text { Is1 enerjisi } \\
\text { gereksinimi } \\
\left(\mathrm{kWh} \cdot \mathrm{m}^{-2} \cdot \mathrm{a}^{-1}\right)\end{array}$ \\
\hline Adana & 83 & 90 \\
\hline Afyon & 173 & 363 \\
\hline Antakya & 99 & 115 \\
\hline Antalya & 91 & 100 \\
\hline Aydın & 104 & 131 \\
\hline Balıkesir & 136 & 237 \\
\hline Bursa & 121 & 219 \\
\hline Çanakkale & 123 & 204 \\
\hline Denizli & 115 & 180 \\
\hline Diyarbakır & 156 & 270 \\
\hline İzmir & 89 & 112 \\
\hline Kahramanmaraş & 125 & 180 \\
\hline Kırşehir & 180 & 360 \\
\hline Kütahya & 166 & 369 \\
\hline Manisa & 116 & 169 \\
\hline Mersin & 73 & 74 \\
\hline Muğla & 128 & 219 \\
\hline Nevşehir & 178 & 376 \\
\hline Ordu & 108 & 179 \\
\hline Samsun & 106 & 175 \\
\hline Sinop & 102 & 194 \\
\hline Şanlıurfa & 120 & 160 \\
\hline Tekirdağ & 129 & 228 \\
\hline Yalova & 106 & 186 \\
\hline
\end{tabular}

Hesaplamalarda seçilen seranın taban alanı 4800 $\mathrm{m}^{2}$, örtü yüzeyi $7338 \mathrm{~m}^{2}$ ve örtü yüzey alanının taban alanına oranı 1,53 olarak kabul edilmiştir.

\section{BULGULAR}

Seralarda enerji verimliliğinin artırılması için alınabilecek önlemler sirasiyla ISIGER uzman sistemle hesaplanarak aşağıda verilmiştir.

\subsection{Seraların teksel olarak kurulması yerine, blok olarak inşa edilmesi}

Seralarda gereksinilen 1s1 enerjisinin azaltılması, enerji verimliliğini artırdığı gibi, fosil enerji kaynaklarının daha az kullanılması nedeniyle, çevre dostu bir üretimin yapılmasına da olanak sağlamaktadır. Seralarda 1Sı kayıplarının ortaya çıktığı örtü yüzey alanının küçültülmesi, enerji kayıplarını azaltacaktır. Belirtilen nedenle seraların teksel olarak kurulması yerine, blok olarak kurulması durumunda, azalan örtü yüzey alanı nedeniyle enerji tasarruf edilecektir. Zabeltitz (1986) yaptığı çalışmada, seraların blok olarak inşa edilmesi durumunda, aynı büyüklükteki teksel seralara oranla $\% 8$ oranında enerjinin tasarruf edilebileceğini belirlemiștir. ISIGER uzman sistem yardımıyla Antalya iklim koşullarında teksel ve blok olarak kurulmuş seralarda birim alan için gereksinilen 1sı enerjisi değerleri hesaplanarak Şekil 1'de verilmiştir. 


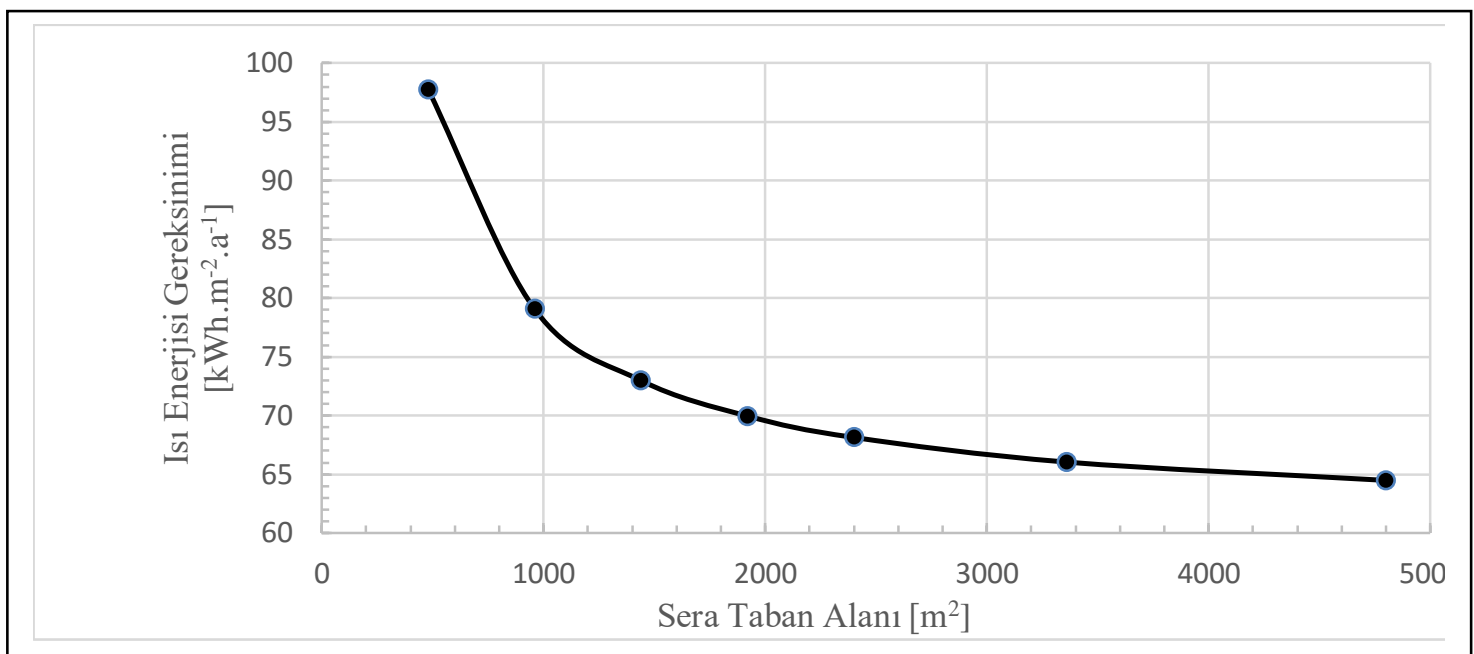

Şekil 1. Birim alan için 1sı enerjisi gereksinimi

Şekilden de görüleceği gibi sera alanı büyüdükçe birim alan için gereksinilen 1S1 enerjisi azalmaktadır. Antalya iklim koşullarında $480 \mathrm{~m}^{2}$ büyüklüğünde 1 sı perdeli 10 adet teksel sera kurulduğunda, birim alan için gereksinilen 1s1 enerjisi $98 \mathrm{kWh} \cdot \mathrm{m}^{-2} \cdot \mathrm{a}^{-1}$ olurken, $4800 \mathrm{~m}^{2}$ büyüklüğünde tek bir blok olarak inşa edilen 1s1 perdeli serada, 1s1 enerjisi gereksinimi \% 34 azalarak $64 \mathrm{kWh} \cdot \mathrm{m}^{-2} \cdot \mathrm{a}^{-1}$ düşmektedir.

\section{2. Örtü malzemesi seçimi ve yalıtımı}

Çizelge 3. Antalya iklim koşullarında gece/gündüz $16 / 18^{\circ} \mathrm{C}$ ve havalandırma sicaklığının $25^{\circ} \mathrm{C}^{\prime}$ ye ayarlandığı koşullarda, farklı örtü malzemesi ile kaplanmış seralarda 1sı enerjisi gereksinimi.

\begin{tabular}{|l|c|c|}
\hline Örtü malzemesi & $\begin{array}{c}\text { Enerji } \\
\text { gereksinimi } \\
\mathrm{kWh} \cdot \mathrm{m}^{-2} \cdot \mathrm{a}^{-1}\end{array}$ & $\begin{array}{c}\text { Cama göre } \\
\text { tasarruf } \\
\text { oranı } \%\end{array}$ \\
\hline Tek katlı cam & 124,6 & - \\
\hline Tek katlı plastik & 114,1 & 8 \\
\hline Çift katlı plastik & 80,6 & 35 \\
\hline PMMA 16 mm aralıklı & 72,2 & 42 \\
\hline $\begin{array}{l}\text { Çatı tek kat PE, Yan } \\
\text { duvar 16 mm PMMA }\end{array}$ & 104,7 & 16 \\
\hline $\begin{array}{l}\text { Çatı tek kat, yan duvar } \\
\text { çift kat PE plastik }\end{array}$ & 106,6 & 14 \\
\hline
\end{tabular}

Seralarda kullanılan örtü malzemesi de 1sı enerjisi gereksinimine etki etmektedir. Antalya iklim koşullarında farklı iç sıcaklık değerlerinde, farklı örtü malzemesi ile kaplanmış seralarda, üretim periyodu boyunca gereksinilen 1sı enerjisi değerleri hesaplanarak, Çizelge 3 'te verilmiştir. Buna göre, çatı ve yan duvarları 16 mm'lik çift katlı PMMA (polimetil meta akrilat) ile örtülmüş serada, tek katlı cam ile örtülmüş seraya göre \% 42 oranında enerji tasarrufu sağlanabilmektedir. Seralarda bitki gelişimi için günlük toplam güneş radyasyonu değerinin $2,34 \mathrm{kWh} \cdot \mathrm{m}^{-2}$. gün ${ }^{-1}$ değerinden büyük olması arzu edilmektedir [8, 11]. Türkiye'de seracılığın yoğun olarak yapıldığı Akdeniz sahil şeridinde bu değer, Aralık ve Ocak aylarında 2 $\mathrm{kWh} \cdot \mathrm{m}^{-2} \cdot$ gün $^{-1}$ değerinden küçüktür. Belirtilen nedenle, kış aylarında, seralarda ısı korunumu amacıyla çok katlı örtü malzemesinin sadece yan duvar ve cephelerde kullanılması önerilmektedir. Serada sadece yan duvar ve cephelerin çift katlı PE plastik ile örtülmesi durumunda tasarruf edilebilecek ısı enerjisi miktarı, tek kat plastikle örtülmüş seraya oranla $\% 7$ olmaktadır.

\subsection{Isı perdeleri}

Seralarda 1S1 enerjisinin korunumu amaciyla tüm dünyada en fazla uygulanan yöntem, 1S1 perdelerinin kullanılmasıdır. Şekil 2'de Türkiye'de seracılığın yaygın olarak yapıldığ Antalya ilinde 


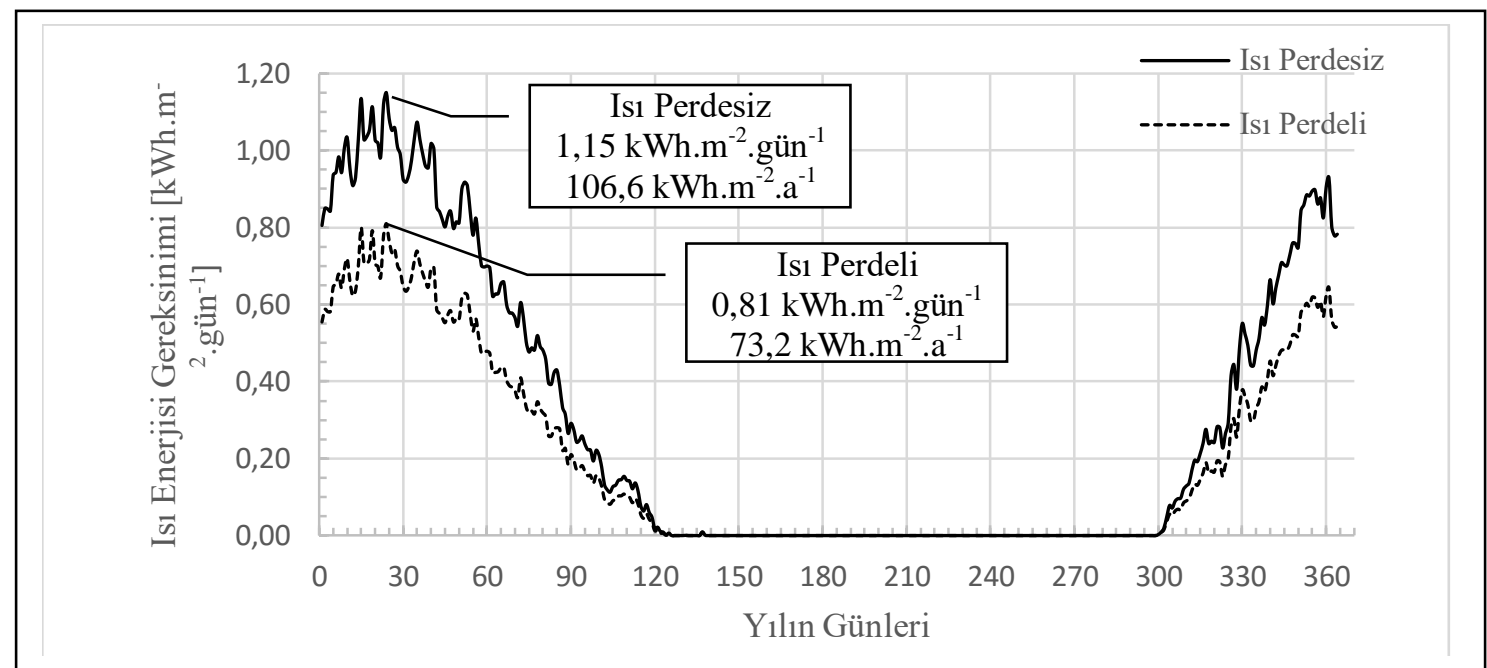

Şekil 2. Antalya ili iklim koşullarında çatısı tek kat, yan duvarları çift kat PE plastikle kaplı ısı perdeli ve perdesiz PE plastik serada sıcaklığın gece/gündüz $16 / 18^{\circ} \mathrm{C}$ 'de tutulduğu koşullarda, günlük 1S1 enerjisi gereksinimi $\left(\mathrm{kWh} \cdot \mathrm{m}^{-2}\right.$.gün $\left.{ }^{-1}\right)$

PE plastik ile kaplı serada, iç sıcaklığın (gece/gündüz) $16 / 18^{\circ} \mathrm{C}^{\prime} d e$ tutulması durumunda, 1sı perdeli ve 1sı perdesiz koşullarda ihtiyaç duyulan günlük ısı enerjisi değerleri verilmiştir. Isı perdesiz PE plastik serada, günlük maksimum 1s1 enerjisi gereksinimi Ocak ayında 1,15 kWh.m ${ }^{2}$.gün ${ }^{-1}$ olarak ortaya çıkmaktadır. Aynı özelliklere sahip 1sı perdeli PE plastik serada ise, gereksinilen günlük maksimum 1sı enerjisi gereksinimi 0,81 $\mathrm{kWh} \cdot \mathrm{m}^{-2}$.gün ${ }^{-1}$ olmaktadır.

Antalya iklim koşullarında isı korumasız ve yan duvarları çift katlı PE plastikle örtülmüş 1sı perdeli $\mathrm{PE}$ plastik serada, sıcaklığın (gece/gündüz) $16 / 18^{\circ} \mathrm{C}^{\prime} \mathrm{de}$ ve havalandırma sicaklığının $25^{\circ} \mathrm{C}^{\prime} \mathrm{de}$ tutulması durumunda, gereksinilen 1S1 enerjisi değerleri Çizelge 4'te verilmiştir. Serada yan duvarların çift katlı PE plastik ile örtülmesi ve 1s1 perdelerinin kullanılması durumunda, \%36 oranında enerji tasarrufu sağlanabilmektedir. $\mathrm{Bu}$ oran enerji verimliliğini artırarak, karlılığ1 yükseltmektedir. Ama daha önemlisi, 1sitmada daha az fosil enerjinin kullanılması nedeniyle, atmosfere verilen $\mathrm{CO}_{2}$ emisyonunun azalmasidır. Seralarda kullanılan 1s1 perdelerinin montajı ve sıdırmazlıkları, tasarruf edilen enerji miktarına etki etmektedir.
Çizelge 4. Antalya ilinde 1 sı korumasız ve yan duvarları yalıtılmış, 1Sı perdeli PE plastik serada, sıcaklığın (gece/gündüz) $16 / 18^{\circ} \mathrm{C}$ ve havalandırma sıcaklığının $25^{\circ} \mathrm{C}$ 'de tutulduğu koşullarda, üretim periyodu boyunca ihtiyaç duyulan isı enerji miktarı.

\begin{tabular}{|c|c|c|}
\hline \multicolumn{2}{|c|}{$\begin{array}{c}\text { Is1 enerjisi gereksinimi } \\
{\left[\mathrm{kWh} \cdot \mathrm{m}^{-2} \cdot \mathrm{a}^{-1}\right]}\end{array}$} & $\begin{array}{c}\text { Tasarruf } \\
\text { oran1 } \\
{[\%]}\end{array}$ \\
\cline { 1 - 2 } Is1 perdeli & Is1 perdesiz & 36 \\
\hline 73,2 & 114,1 & 36 \\
\hline
\end{tabular}

Seralarda 1s1 perdelerinin yan duvar ve cephelerle birleştiği yerlerde sızdırmazlık önem kazanmaktadır. İyi yalıtılmamış 1sı perdelerinde, ısınan havanın yükselerek bu aralıklardan geçip çatı bölgesinde birikmesi nedeniyle, 1s1 perdelerinden beklenen 1sı tasarrufunun sağlanması mümkün olmamaktadır. Antalya iklim koşullarında PE plastik serada, 1Sı perdelerinin sızdırmazlıklarına bağlı olarak hesaplanan 1s1 enerjisi gereksinimi ve tasarruf oranları, Çizelge 5 'te verilmiştir. Perdelerin sızdırmazlıklarına bağlı olarak tasarruf edilebilen 1s1 enerjisi oran1 \% 7-31 arasında değişim göstermektedir. 
Çizelge 5. Antalya koşullarında çatısı tek kat, yan duvarları çift kat PE plastik ile örtülmüş serada, kullanılan ısı perdelerinin sızdırmazlıklarına bağlı olarak, sıcaklığın (gece/gündüz) 16/18 ${ }^{\circ} \mathrm{C}$, ve havalandırma sıcaklığının $25^{\circ} \mathrm{C}$ 'ye ayarlandığı koşullarda üretim periyodu boyunca gereksinilen 1s1 enerjisi

\begin{tabular}{|c|c|c|c|c|c|c|}
\hline \multicolumn{3}{|c|}{ Is1 enerjisi gereksinimi $\left[\mathrm{kWh} \cdot \mathrm{m}^{-2} \cdot \mathrm{a}^{-1}\right]$} & \multicolumn{4}{c|}{ Tasarruf oranı [\%] } \\
\hline \multirow{3}{*}{ Is1 perdesiz } & \multicolumn{3}{|c|}{ Perde sızdırmazlığ1 } & Orta & Kötü \\
\cline { 2 - 7 } & İyi & Orta & Kötü & İyi & 19 & 7 \\
\hline 106,6 & 73,2 & 86,1 & 98,9 & 31 & 19 \\
\hline
\end{tabular}

\subsection{Isıtma Sistemi}

Seralarda tercih edilen kültür çeşidine bağlı olarak farklı 1sıtma sistemleri kullanılmaktadır. Seralarda 1S1 enerjisi tüketimi, seçilen 1sıtma sisteminin tipine bağlı olarak değişim göstermektedir. Antalya iklim koşullarında farklı 1sıtma sistemlerinin kurulduğu, yan duvarları çift kat, çatısı tek kat PE plastik ile örtülmüş 1sı perdeli serada, farklı 1sıtma sistemlerine bağlı olarak, üretim periyodu boyunca gereksinilen isı enerjisi değerleri $\left(\mathrm{kWh} \cdot \mathrm{m}^{-2} \cdot \mathrm{a}^{-1}\right)$ Çizelge 6 'da verilmiştir.

Çizelge 6'ya göre, en yüksek 1s1 enerjisi gereksinimi, ısıtma borularının sera çatısına yakın yerleştirilmesi durumunda ortaya çıkmaktadır. Isıtma borularının sera tabanına yakın yerleştirilmesi durumunda gereksinilen 1Sı enerjisi, yükseğe yerleştirilmiş borulu ısıtma sistemine göre $\% 18$ oranında azalmaktadır. Bu nedenle seralarda enerji tasarrufu amaciyla 1sıtma boruları mümkün olduğunca sera tabanına yakın yerleştirilmelidir.

\subsection{Isıtma kazanının seçimi}

Isıtılan seralarda maksimum 1sı gücünün belirlenmesi yanında, yıl içindeki 1sı gücü tekerrürlerinin bilinmesi, 1sıtma sistemi için seçilecek kazan boyutlarının belirlenmesinde ve 1sıtmanın yönetiminde önem arz etmektedir. Şekil 3 'te Antalya iklim koşullarında 1sı perdeli ve 1s1 perdesiz plastik serada, sıcaklığın (gece/gündüz) $16 / 18^{\circ} \mathrm{C}^{\prime}$ de tutulması durumunda, gerekli olan is1 gücü değerleri ve tekerrürleri verilmiştir. Şekilden de görüleceği gibi, Antalya iklim koşullarında iç sicaklığın gece/gündüz $16 / 18^{\circ} \mathrm{C}^{\prime} \mathrm{de}$ tutulması durumunda, yılın 2510 saatinde 1sıtmaya ihtiyaç duyulmaktadır. $\mathrm{Bu}$ koşullarda serada ihtiyaç duyulan maksimum 1s1 gücü gereksinimi 91 W. ${ }^{-2}$, dir. Serada 1s1 perdesinin kullanılması durumunda, ısı gücü gereksiniminde hızlı bir azalma ortaya çıkmaktadır. Antalya iklim koşullarında, iyi yalıtılmış 1sı perdeli serada, 60 W.m ${ }^{-2}$ 1sı gücüyle yılın 101 saati dışında seradaki sıcaklık $16 / 18^{\circ} \mathrm{C}$ 'de tutulabilecektir.

Çizelge 6. Antalya iklim koşullarında çatısı tek kat, yan duvarları çift kat PE plastik ile örtülmüş 1Sı perdeli serada, sıcaklığın gece/gündüz $16 / 18^{\circ} \mathrm{C}$ 'de tutulması durumunda, farklı ısıtma sistemlerine bağlı üretim periyodu boyunca gereksinilen 1sı enerjisi değerleri

\begin{tabular}{|c|c|c|}
\hline Isitma sistemi & $\begin{array}{l}\text { Isı enerjisi } \\
\text { gereksinimi } \\
\left(\mathrm{kWh} \cdot \mathrm{m}^{-2} \cdot \mathrm{a}^{-1}\right)\end{array}$ & $\begin{array}{c}\text { Yükseğe yerleştirilmiş } \\
\text { borulu 1sitma sistemine } \\
\text { oranla tasarruf yüzdesi } \\
(\%)\end{array}$ \\
\hline Yükseğe yerleştirilmiş borulu 1sıtma sistemi & 79,1 & 0 \\
\hline Masa altı borulu 1sitma sistemi & 71,6 & 9 \\
\hline Tabana yakın borulu isitma sistemi & 64,5 & 18 \\
\hline Vejetasyon 1sitmasi & 64,5 & 18 \\
\hline Plastik tüplü üfleyicili ısıtma sistemi & 67,4 & 15 \\
\hline
\end{tabular}




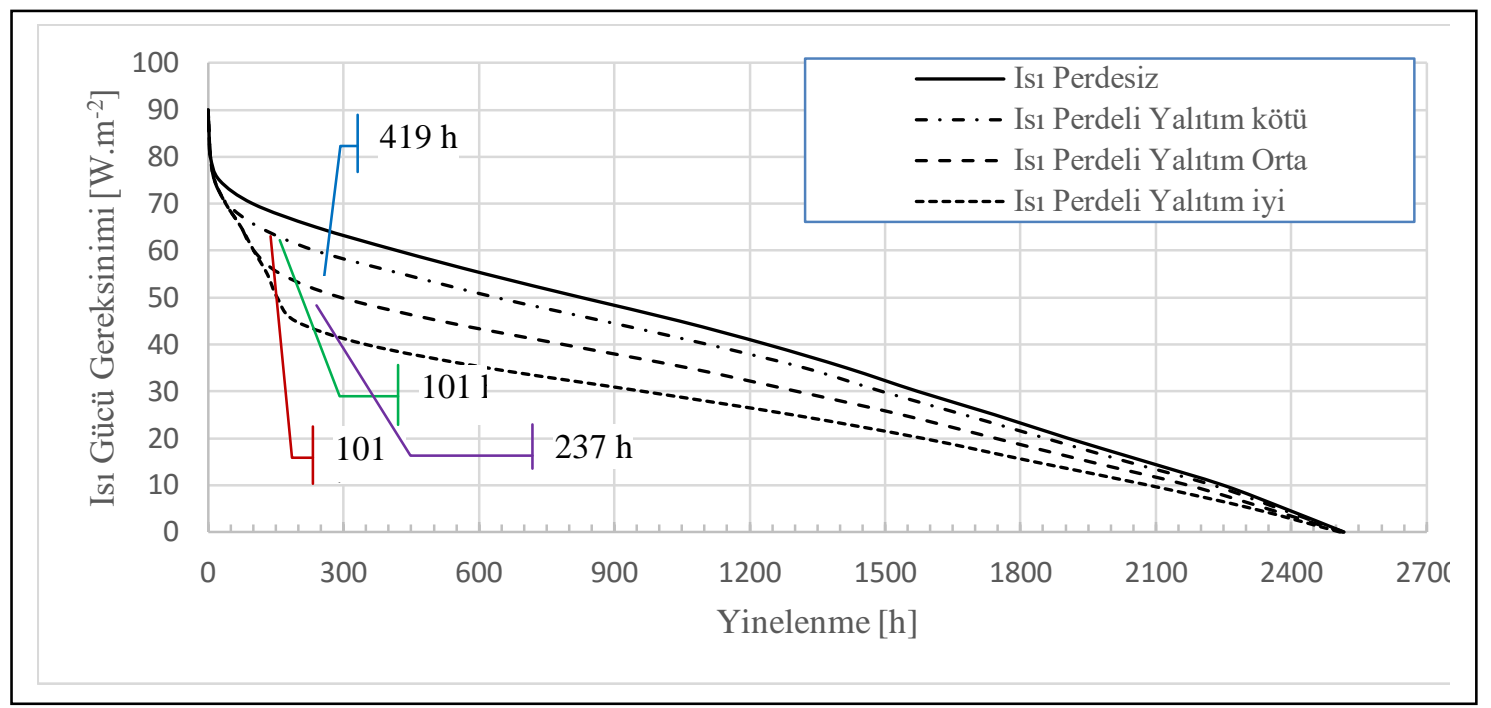

Şekil 3. Antalya ili iklim koşullarında normal ve ısı korumalı plastik serada sıcaklığın gece/gündüz $16 / 18^{\circ} \mathrm{C}^{\prime}$ de tutulması durumunda $1 \mathrm{~S} 1$ perdelerinin sizdırmazlıklarına bağlı olarak ortaya çıkan 1 sı gücü tekerrürleri (Havalandırma sıcaklı̆ $125^{\circ} \mathrm{C}$ )

Diğer bir ifade ile $60 \mathrm{~W} \cdot \mathrm{m}^{-2} 1 \mathrm{~s}$ gücüne sahip 1 sitma sistemiyle, iyi ve orta yalıtılmış isı perdeli serada yılın 101 saati dışında, sızdırmazlığı kötü olan isı perdeli serada yılın 237 saati dışındaki zamanlarda, sicaklık arzulanan değerlerde $\left(16 / 18^{\circ} \mathrm{C}\right)$ tutulabilmektedir. Belirtilen koşullarda seranın temel 1S1 ihtiyacını karşılayacak kazan büyüklüğünün belirlenmesinde, üreticinin serada 1sı korunumu için kullanılan önlemleri iyi takip etmesi zorunludur.

Seralarda tek bir 1sıtma kazanı yerine iki ayrı kazanın seçilmesi önerilmektedir. $\mathrm{Bu}$ durum, seranın temel 1s1 ihtiyacını karşılayacak kazan boyutunun küçülmesine, dolayısı ile ilk yatırım ve 1sitma giderlerinde tasarruf edilmesine olanak sağlayacaktır. Antalya iklim koşullarında 4800 $\mathrm{m}^{2}$ lik $1 \mathrm{~s} 1$ perdeli (sızdırmazlık orta) serada sicaklı̆ğın gece/gündüz $16 / 18^{\circ} \mathrm{C}^{\prime}$ de tutulmak istenmesi durumunda, gereksinilen maksimum 1S1 gücü $430 \mathrm{~kW}$, toplam 1s1 enerjisi gereksinimi 364 MWh olmaktadır (Şekil 4). $430 \mathrm{~kW}$ isı gücüyle serada tüm yıl boyunca sıcaklığın $16 / 18^{\circ} \mathrm{C}^{\prime} \mathrm{de}$ tutulması mümkün olabilmektedir. Kurulacak olan 1sıtma sisteminde seranın temel 1sı enerjisi gereksinimini karşılamak amacıyla $150 \quad \mathrm{~kW}$ büyüklüğünde bir kazanın seçilmesi durumunda, seranı temel 1S1 ihtiyacı olan 285 MWh (\% 79) karşılanabilecektir. Isıtma sistemi için seçilecek ikinci kazanın büyüklüğü $430 \mathrm{~kW}$ olduğunda seranın ekstrem durumlarda ortaya çıkacak isı enerjisi gereksiniminin karşılanması mümkün olabilecektir.

\section{6. İklimlendirme (Otomasyon)}

Seralarda bitki gelişim etmenlerinin düzenlenmesinde bilgisayarların kullanılması, gelişim etmenlerinden sicaklık ve nemin, bitkilerin arzuladıkları biyolojik optimum değerlerde tutulmasını sağlarken, aynı zamanda enerji tasarrufuna da olanak sağlamaktadır. Seralarda 1şı, sıcaklık, nem ve $\mathrm{CO}_{2}$ değerlerinin bitkinin arzuladığ 1 değerlerde tutulması ve bu gelişim etmenlerinin birbirine olan etkileşimine bağlı olarak sera ortamının bilgisayarlarla kontrolü, serada enerji tasarrufu ve bitki gelişimi açısından önemlidir. Büyük işletmeler halinde kurulan modern seralarda, iç ortam denetiminin Bilgisayarlarla gerçekleştirilmesi enerji tasarrufu 


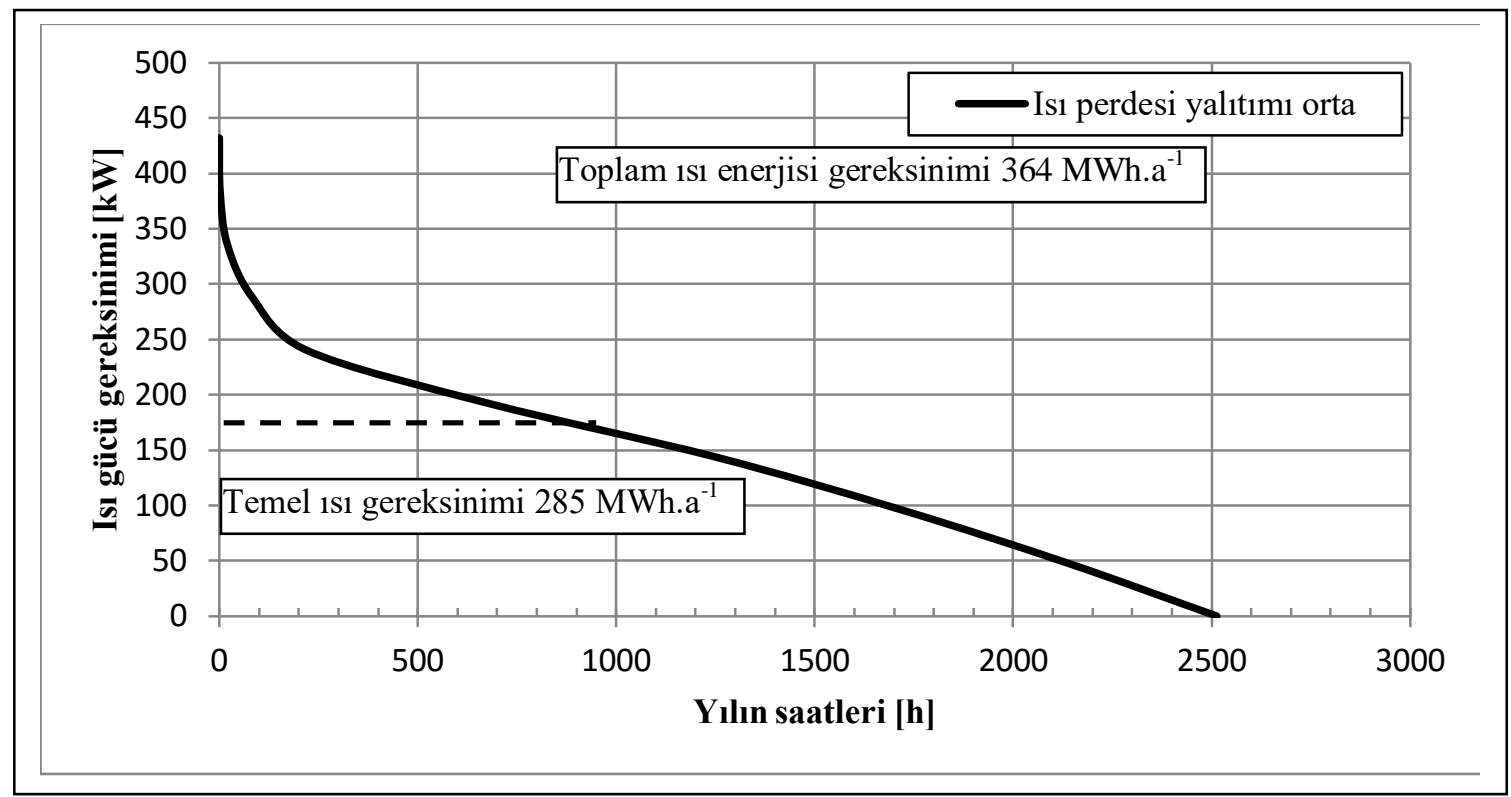

Şekil 4. Antalya iklim koşullarında $4800 \mathrm{~m}^{2}$ büyüklüğünde, yalıtımı orta derecede olan 1Sı perdeli serada gece/gündüz sıcaklık değerlerinin $16 / 18^{\circ} \mathrm{C}$ 'de tutulması durumunda gerekli olan isı gücü ve toplam 1 sı enerjisi gereksinimi

yanında iş gücü tasarrufu da sağlamaktadır. Sera iç ortam denetiminde bilgisayarların kullanılması, iklim etmenlerinin kontrolünde yeni stratejilerin geliştirilmesini sağlamıştır. Serada sıcaklık değerlerinin kontrolünde, günlük toplam sıcaklık değerleri dikkate alınarak, serada sıcaklık değerleri düzenlenmektedir. Gündüz saatlerinde serada sıcaklık, bitkilerin arzuladığı biyolojik optimumun üst sınırında tutularak, gece saatlerinde alt sinır değerlerine kadar düşmesine izin verilmektedir.

Seralarda iç ortam denetiminin sıcaklık toplamına göre yapılması durumunda, \% 15 oranında 1s1 enerjisinin tasarruf edilebileceği belirlenmiştir. $\mathrm{Bu}$ koşullarda serada gece sicaklık değerlerinin 13$14^{\circ} \mathrm{C}^{\prime}$ ye kadar düşmesine müsaade edilmektedir. Ancak bu durumda, serada nem değerlerinin takibe alınması büyük bir önem arz etmektedir. Serada özellikle gece saatlerinde ortaya çıkan yüksek nem, 1sıtma ile kontrol edilemediği durumlarda, havalandırma sistemlerinin 1sitma ile birlikte devreye girmesine neden olabilmektedir. $\mathrm{Bu}$ durum ciddi anlamda enerji kaybina neden olmaktadır.
Böyle durumlarda iç ortam iklim etmenlerini denetleyen bilgisayar, denetim elemanlarından üç yollu vanaları kısarak, seraya ulaşan isı enerjisini düzenlemekte ve havalandırma kapaklarını çok kısa süreli tam açarak nemi kontrol edebilmektedir.

Seralarda havalandırma sıcaklığının yüksek tutulmasi, serada az da olsa bir enerji tasarrufuna neden olmaktadır. $\mathrm{Bu}$ oran gündüz sera sıcaklığının enerji tasarrufu amacıyla düşük tutulması durumunda biraz daha artmaktadır.

Çizelge 7'de Antalya iklim koşullarında serada sicaklığın gece/gündüz $16 / 18^{\circ} \mathrm{C}$ 'de ve havalandırma sıcaklığının $19-26^{\circ} \mathrm{C}$ de tutulduğu yan duvarları izoleli, 1sı perdeli plastik serada, gereksinilen yıllık ısı enerjisi değerleri verilmiştir.

Çizelgeden de görüleceği gibi, havalandırma sıcaklığının bitkinin dayanabileceği üst sinırlarda tutulması $\% 3$ enerji tasarrufu sağlamaktadır. 
Çizelge 7. Antalya iklim koşullarında çatısı tek kat yan duvarları çift kat PE plastikle kaplı 1sı perdeli (yalıtımı iyi) serada, sıcaklığın gece/gündüz $16 / 18^{\circ} \mathrm{C}^{\prime}$ de tutulması durumunda, farklı havalandırma sıcaklıklarında gereksinilen 1sı enerjisi değerleri

\begin{tabular}{|c|c|c|c|}
\hline \multirow[t]{3}{*}{ Sera tipi } & \multirow{2}{*}{\multicolumn{2}{|c|}{$\begin{array}{c}\text { Is1 enerjisi gereksinimi } \\
{\left[\mathrm{kWh} \cdot \mathrm{m}^{-2} \cdot \mathrm{a}^{-1}\right]}\end{array}$}} & \multirow{3}{*}{$\begin{array}{c}\text { Enerji } \\
\text { tasarruf oran } \\
\%\end{array}$} \\
\hline & & & \\
\hline & $19^{\circ} \mathrm{C}$ & $26^{\circ} \mathrm{C}$ & \\
\hline $\begin{array}{l}\text { Çatısı tek kat, yan duvarları çift kat PE plastikle kapl, } \\
\text { yalıtımı iyi 1sı perdeli PE plastik Sera (Gece / Gündüz } \\
16 / 18^{\circ} \mathrm{C} \text { ) }\end{array}$ & 66,0 & 64,3 & 3 \\
\hline
\end{tabular}

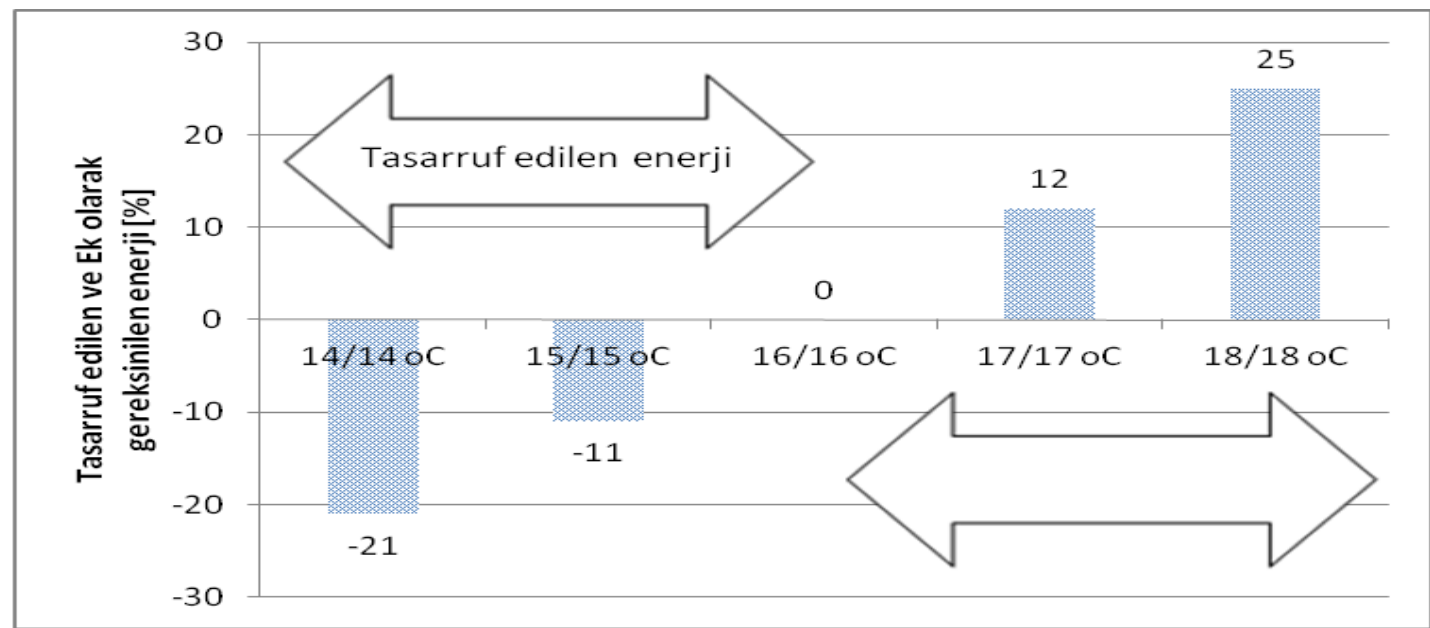

Şekil 5. Serada sıcaklığın gece/gündüz $16^{\circ} \mathrm{C}$ 'de tutulduğu $\mathrm{PE}$ plastik serada, sıcaklığın $16^{\circ} \mathrm{C}$ 'den sapmasına bağlı olarak tasarruf edilen ve ek olarak gereksinilen 1sı enerjisi yüzdesi (\%)

\subsection{Uygun ölçüm algılayıcılarının kullanılması}

Seralarda kontrol bilgisayarlarına veri sağlayan algılayıcıların mümkün olduğu kadar bitki sıra aralarına yakın yerleştirilmesi, bakım ve kalibrasyonları enerji tüketimine etki etmektedir. Serada sıcaklık algılayıcıları doğrudan güneş ışınlarını almayacak şekilde hava sirkülasyonuna sahip koruyucular içinde olmalıdırlar. Serada yapılan ölçüm hataları, ortam klimasının düzenlenmesinde hataların ortaya çıkmasına neden olabileceği gibi, daha fazla enerjinin serada tüketilmesine de neden olabilmektedir. Serada sıcaklı̆ı̆ı kontrol bilgisayarları tarafindan düzenlemesinde ortaya çıkan sapmaların büyüklüğü, bitkide stres yaratacağı gibi, enerji kayıplarına da neden olabilmektedir. Şekil 5'te sıcaklığın gece/gündüz $16^{\circ} \mathrm{C}^{\prime}$ ye ayarlandığı $\mathrm{PE}$ plastik serada, sicaklık değerlerindeki sapmalara $( \pm)$ bağlı olarak ortaya çıkan 1sı enerjisi gereksinimi sapmaları verilmiştir. Şekil 5, her $\pm 1^{\circ} \mathrm{C}^{\prime}$ lik sıcaklık sapması yaklaşık $\pm \% 10$ oranında enerji değişimi olduğunu göstermektedir.

\section{SONUC}

Seralarda 1sıtma, verim artışı yanında ürün kalitesine olumlu yönde etki etmektedir. Ancak 1sıtma üretim maliyetini artırdığ 1 gibi, fosil enerji kaynaklarının kullanılması durumunda, atmosfere 
verilen $\mathrm{CO}_{2}$ emisyonu nedeniyle çevreye zarar vermektedir. Isitılan seralarda 1sitma kadar, 1S1 enerjisinin korunumu, diğer bir ifade ile enerji verimliliğinin artırılmasını zorunlu hale gelmiştir. Seralarda 1sı kaybına neden olan yüzey alanlarının küçültülmesi, ısı iletim direnci yüksek olan örtü malzemesinin kullanılması, 1sı perdelerinin doğru montajı ve kullanılması, uygun 1sitma sistemlerinin seçilmesi ve boyutlandırılması ve uygun sulama sistemlerinin seçilmesi, seralarda ciddi anlamda enerjinin tasarruf edilmesine ve enerji verimliliğinin yükseltilmesine olanak sağlamaktadır.

Ancak, verilen bu oranlara ulaşmak için alınan önlemlerin doğru projelenmesi ve işletilmesi zorunludur. Aynı zamanda 1S1 tasarrufu için yapılan yatırımların, tasarruf edilen enerji miktarı ile karşılaştırılması üretim ekonomisi açısından önemlidir. Ancak enerji verimliliğinin artırılması amacıyla gereksinilen 1sı enerji değerinin düşürülmesinde, atmosfere verilen $\mathrm{CO}_{2}$ emisyonunun göz ardı edilmemesi önemlidir.

\section{KAYNAKLAR}

1. Baytorun, A. N., Akyüz, A., Üstün, S., 2015. Seralarda Isitma Sistemlerinin Modellemesi ve Karar Verme Aşamasında Bilimsel Verilere Dayalı Uzman Sistemin Geliştirilmesi. TÜBİTAK 1140533 nolu proje. Yayın aşamasında.

2. Bot, G., 2008. Greening the Greenhouse General consideration.

3. Campiotti,C.A., Dondi, F., 2007. ENEA Casaccia, dpt. BASE mail: campiotti@casaccia.enea.it

4. De Pascale, S., Maggio, A., 2005. Acta Horticulturea, 691, s. 29-36.

5. Giuliano, V., Teitel, M., Pardossi, A., Minuto, A., Tinivella, F., Schettini, E., 2010. Sustainable Greenhouse Systems. Sustainable Agriculture. ISBN: 978-1-60876-269-9. Nova Science Publishers, Inc.

6. Horscht, M., Ludolph, D., Bessler, B., Akyazı, G., Knösel, K., Tantau, H.J., 2014. Niedrigenergiegewachshaus Mit Maximaler Warmedammung und Solarwarmenutzung. Zukunftsinitiative
Niedrigenergiegewachshaus. Ansatze und Ergebnisse. KTBL Darmstadt.

7. Munoz, P., Anton, A., Nunez, M., Paranjpe, A., Arino, J., Castells,Y., Montero,J., Rieradevall, J., 2008. Acta Horticulturea. 801 (2), 1591-1596.

8. Nisen, A., Grafiadellis, M., Jiménez, R., La Malfa, G., Martiez-Garcia, P,F., Monteiro, A., Verlodt, H., Villele, O., Zabeltitz, C,v., Denis, J,C., Boudoin,W., Garnaud, J.c., 1988. Cultures Protegees en Climat Mediterranean, FAO, Rome.

9. Russo, G., Delucia Zeller, B., 2008. Acta Horticulturea. 801, 1597-1604.

10. Zabeltitz, C, von. 1986. Gewachshauser. Verlag Eugen Ulmar. Stuttgart.

11. Zabeltitz, C, von., 1992. Energy-Efficient Greenhouse Designs for Mediterranean countries. Plasticulture no.96 1992/24. s.6-16.

12. Zabeltitz, C, von., 2011. Integrated Greenhouse Systems for Mild Climates. Climate Conditions, Desing, Construction, Maintenance, Climate Control. SpringerVerlag Berlin Heidelberg. 
